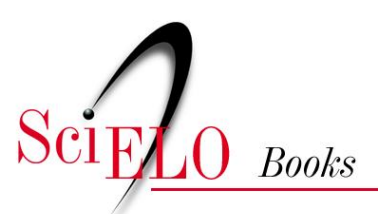

\title{
3. Sistemática e evolução dos vetores
}

\author{
Cleber Galvão \\ Alexandre Silva de Paula
}

\section{SciELO Books / SciELO Livros / SciELO Libros}

GALVÃO, C., and PAULA, AS. Sistemática e evolução dos vetores. In: GALVÃO, C., org. Vetores da doença de chagas no Brasil [online]. Curitiba: Sociedade Brasileira de Zoologia, 2014, pp. 26-32. Zoologia: guias e manuais de identificação series. ISBN 978-85-98203-09-6. Available from SciELO Books $<$ http://books.scielo.org $>$.

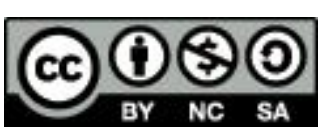

All the contents of this chapter, except where otherwise noted, is licensed under a Creative Commons Attribution-Non Commercial-ShareAlike 3.0 Unported.

Todo o conteúdo deste capítulo, exceto quando houver ressalva, é publicado sob a licença Creative Commons Atribuição Uso Não Comercial - Partilha nos Mesmos Termos 3.0 Não adaptada.

Todo el contenido de este capítulo, excepto donde se indique lo contrario, está bajo licencia de la licencia Creative Commons Reconocimento-NoComercial-CompartirIgual 3.0 Unported. 


\section{Sistemática e evolução dos vetores}

\section{(Cleber Galvão \& Alexandre Silva de Paula)}

"Deus criou, Linnaeus organizou"

(Carolus Linnaeus)

Modelos matemáticos estimam em cerca de dez milhões o número de espécies de seres vivos que podem existir sobre a terra (somando-se as espécies conhecidas e as ainda desconhecidas). O número de espécies já descritas, porém, é muito inferior e não chega a dois milhões (May 1992, Wilson 1992). Toda essa enorme biodiversidade, para ser estudada, precisa ser organizada em categorias ou grupos. A importância dessa classificação é fundamental e dessa tarefa se incumbem os taxonomistas.

O sueco Carolus Linnaeus (1707-1778) é o autor do primeiro sistema consistente de classificação. Tudo começou em 1735 com a publicação da primeira versão da obra Systema Naturae. Essa publicação, de apenas 11 páginas, propôs um sistema de classificação que usa como critério órgãos, estruturas morfológicas e estruturas reprodutivas de animais e plantas. É um sistema simples que substitui as longas denominações de espécies que vigoravam na Europa até então, procurando estabelecer critérios mais objetivos para a classificação de animais e plantas. Linnaeus propôs categorias hierárquicas e um sistema binomial de classificação no qual a denominação dos seres vivos utilizaria dois nomes em latim ou latinizados, um nome para o gênero e outro específico, e o conjunto dessas duas palavras forma o nome da espécie. A praticidade desse sistema é responsável pelo enorme sucesso da chamada Taxonomia Lineana, que mesmo tendo sido criada há mais de 200 anos é usada até os dias de hoje.

A primeira grande subdivisão dos animais é o filo, que se subdivide em classes, estas se subdividem em ordens, estas em famílias, as famílias em gêneros e estes em espécies. Existem ainda diversas divisões intermediárias como, por exemplo, subfamílias e tribos. A figura 3.1 mostra toda a hierarquia das categorias taxonômicas aceitas pelos zoólogos para os diversos grupos ani-

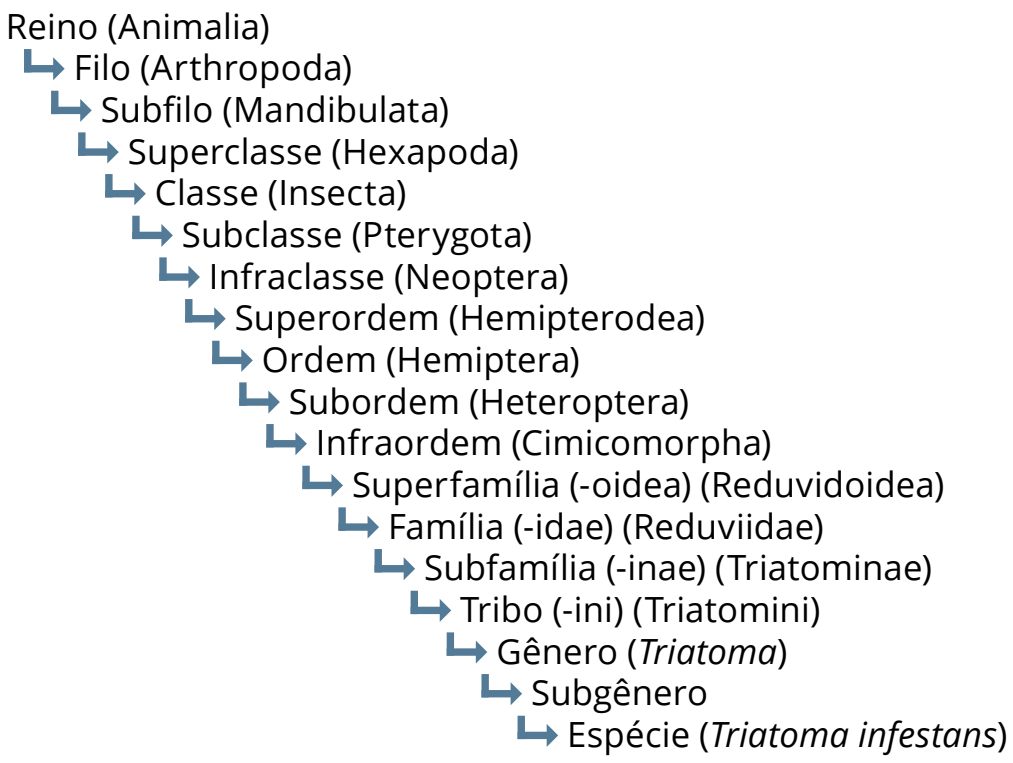

Figura 3.1: Hierarquia das categorias taxonômicas zoológicas, utilizando a classificação da espécie Triatoma infestans como exemplo. Observe que as categorias superfamília, família, subfamília e tribo possuem um sufixo próprio que permite diferenciá-las facilmente das demais categorias. 
mais. Entre parênteses, exemplificamos o posicionamento da espécie Triatoma infestans (Klug, 1834).

No filo Arthropoda estão incluídos, entre outros, os insetos. As principais características dos artrópodes são a simetria bilateral, a presença de pernas articuladas e de um exoesqueleto (esqueleto externo duro e resistente, formando uma espécie de carapaça que protege e sustenta os órgãos internos). São exemplos de artrópodes o camarão, o escorpião, a vespa e o barbeiro (Figura 3.2).

Dentro do filo Arthropoda há diversas classes e na classe Insecta estão incluídos todos os insetos que se caracterizam por possuírem o corpo dividido em cabeça, tórax e abdômen, três pares de pernas articuladas e um par de antenas (Figura 3.3). A classe Insecta está dividida em diversas ordens, dentre elas a ordem Hemiptera, cuja principal característica diagnóstica é a presença do aparelho bucal picador-sugador.

A despeito do nome da ordem (Hemi=metade, ptera=asa), a presença dos hemélitros ou hemiélitros (asa com a parte basal espessada e coriácea e a apical membranosa (Figura 3.4) não

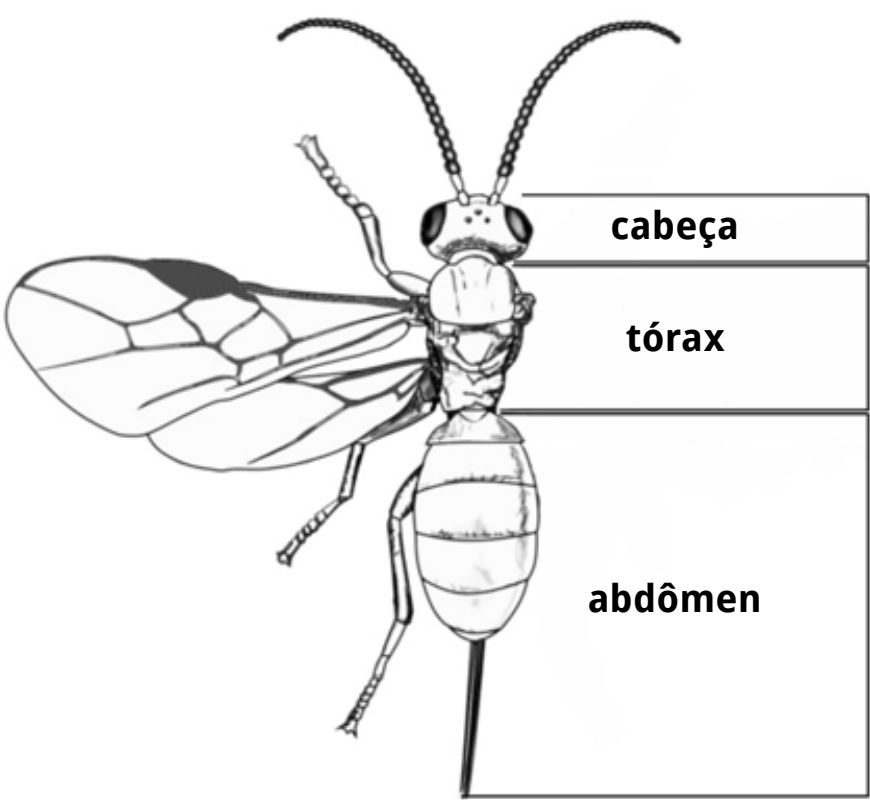

Figura 3.3: As três principais divisões do corpo de um inseto.

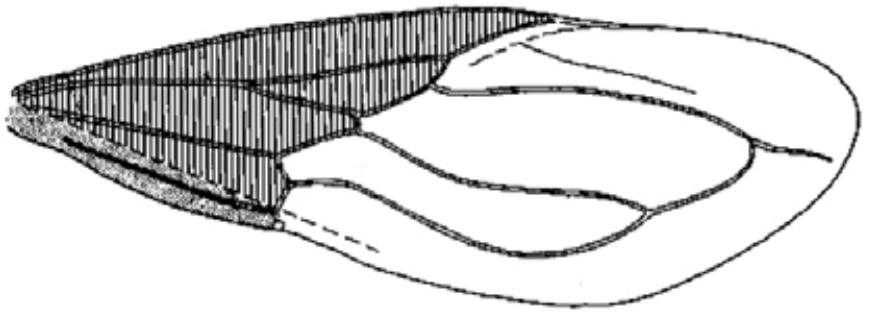

Figura 3.4: Hemélitro: tipo de asa encontrada em diversos membros da ordem Hemiptera. ocorre em todos os hemípteros e, portanto, essa característica não pode ser considerada diagnóstica para a ordem. A maioria das espécies é terrestre, porém, algumas são aquáticas. Muitas sugam plantas (fitófagas), outras são predadoras de outros insetos (entomófagas) e algumas sugam sangue (hematófagas). Esta ordem se subdivide nas subordens Coleorrhyncha, Auchenorrhyncha, Sternorrhyncha (anteriormente reunidas numa subordem chamada Homoptera) e Heteroptera que abriga os insetos conhecidos vulgarmente como percevejos (Maddison, 1995).

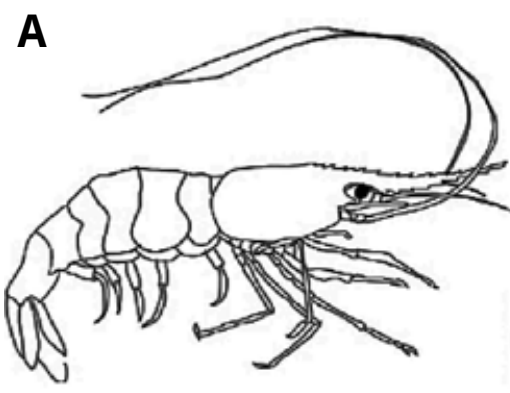

B

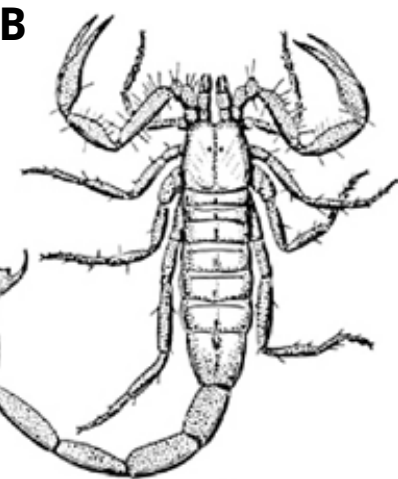

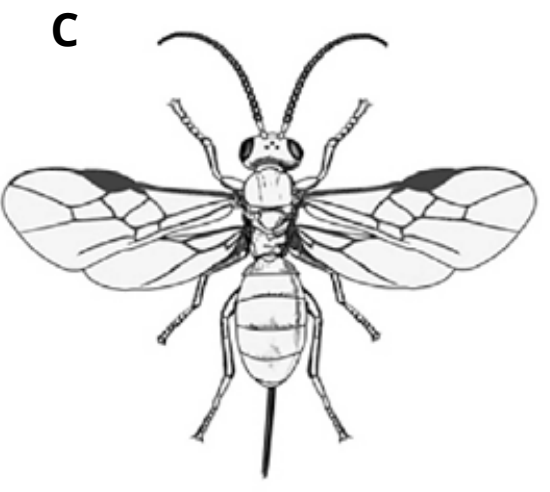

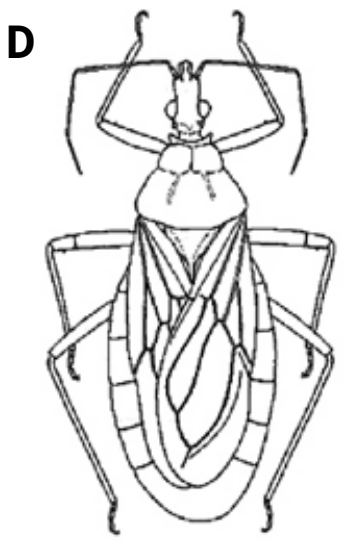

Figura 3.2: Exemplos de artrópodes - A: camarão; B: escorpião; C: vespa; D: barbeiro. 
Das numerosas famílias de hemípteros, apenas duas tem interesse na medicina humana devido ao hábito hematofágico de suas espécies: Cimicidae (percevejos de cama) e Reduviidae. O número de subfamílias que compõem a família Reduviidae varia segundo diferentes especialistas. China \& Miller (1959) reconhecem 29 subfamílias, Maldonado Capriles (1990) reconhece 25 subfamílias, Putchov \& Putchov (1985 apud Schuh \& Slater 1995) reconhecem 21 subfamílias e Schuh \& Slater (1995) reconhecem 22. Apenas uma subfamília (Triatominae) realiza hematofagia, as demais subfamílias são compostas por insetos predadores (também chamados entomófagos) (Figura 3.5).

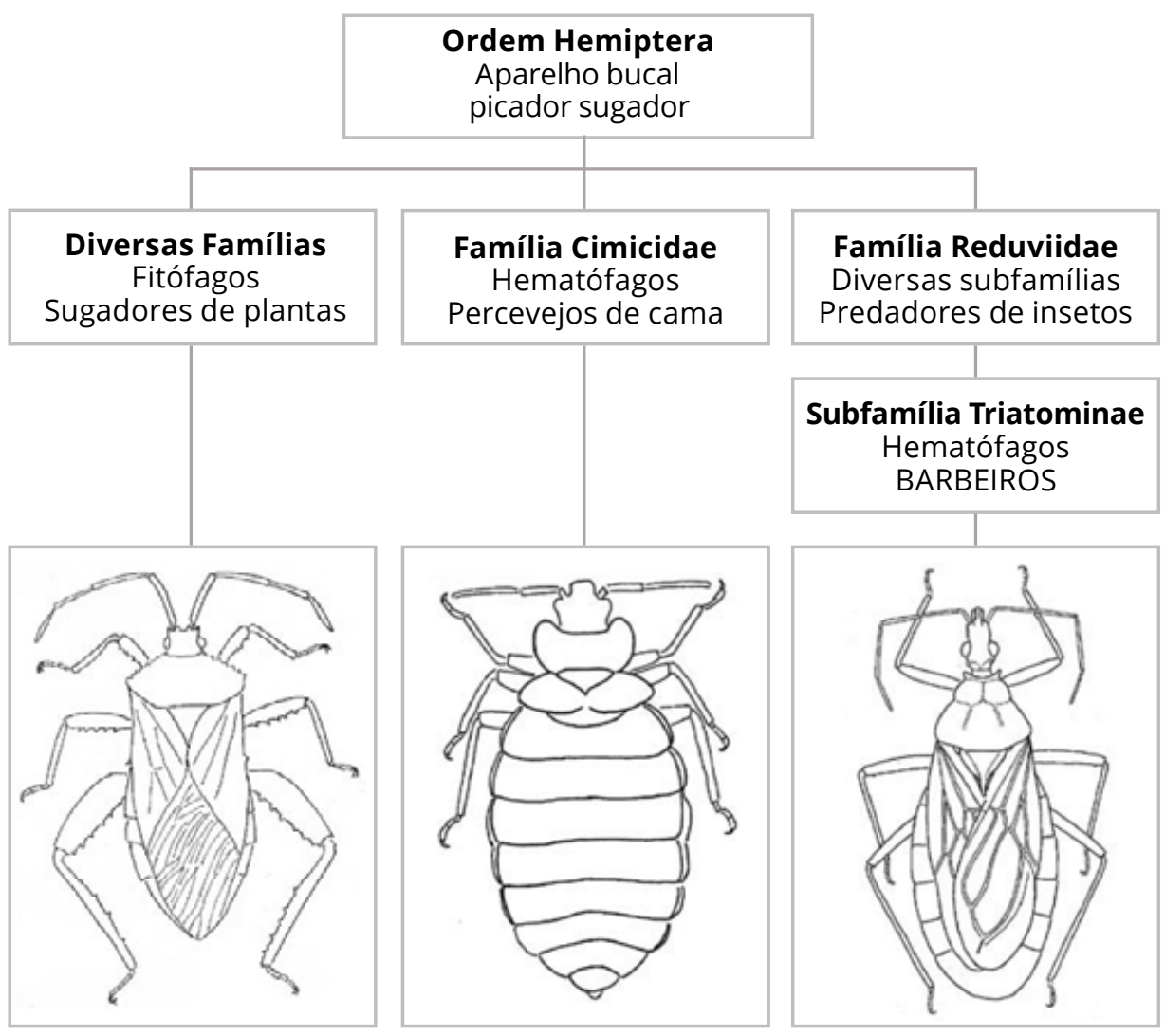

Figura 3.5: As ilustrações (em escalas diferentes) mostram representantes de hemípteros fitófagos e das duas famílias nas quais existem espécies hematófagas.

A décima edição do Systema Naturae, publicada por Carolus Linnaeus em 1758, foi subsequentemente designada pela comunidade de zoólogos como o ponto de partida para a aplicação das regras de nomenclatura binomial zoológica. Essa edição [Systema Naturae] já incluía a criação da ordem Hemiptera, entretanto, os estudos taxonômicos dos triatomíneos só começaram com a publicação Mémoire pour servir à l'histoire des insectes (De Geer, 1773), na qual a primeira espécie foi descrita como Cimex rubrofasciatus. Sessenta anos mais tarde, ela foi designada por Laporte (1833) como espécie-tipo do gênero Triatoma, passando a ser chamada Triatoma rubrofasciata. 0 gênero Triatoma foi proposto por Laporte em uma descrição baseada em espécimes com antenas quebradas, mostrando apenas três dos quatro artículos antenais (Triatoma = três artículos). Examinando novos espécimes e percebendo seu erro, ele propôs a mudança do nome genérico para Conorhinus (= nariz de cone), mas o nome genérico Triatoma já tinha prioridade e permaneceu válido (ICZN 1999).

A classificação atual da subfamília Triatominae está baseada principalmente na revisão de Lent \& Wygodzinsky (1979), entretanto, desde sua publicação novas espécies foram descritas e outras foram revalidadas ou sinonimizadas. A classificação tradicional dos triatomíneos baseia-se predominantemente em caracteres morfológicos, entretanto, novas comparações baseadas em caracteres moleculares (sequências de DNA) algumas vezes têm desafiado o conceito morfológico e há algumas dificuldades em se obter uma classificação estável e consensual do grupo. Neste livro, apresentamos um resumo da atual classificação, atualizada pelas publicações de Galvão (2003), Galvão et al. (2003), Forero et al. (2004), Garcia et al. (2005), Galvão \& Angulo (2006), Costa et al. (2006), Costa \& Felix 
(2007), Sandoval et al. (2007), Berenguer \& Blanchet (2007), Martínez et al. (2007), Schofield \& Galvão (2009), Ayala (2009), Frías-Lasserre (2010), Rosa et al. (2012), Gonçalves et al. (2013), Jurberg et al. (2013) e Abad-Franch et al. (2013). Atualmente, são reconhecidas formalmente 148 espécies recentes e duas espécies fósseis (Tabela 3.1) embora algumas delas possam futuramente vir a ser consideradas meramente como variações populacionais. Por outro lado, com a crescente pesquisa de campo, é provável que sejam encontradas novas variantes, algumas das quais poderão merecer descrição formal como espécies novas.

Embora seja reconhecida por vários autores como uma subfamília monofilética de Reduviídeos (com um único ancestral comum para todas as espécies da subfamília), adaptados à
Tabela 3.1 - Classificação sistemática atual da subfamília Triatominae

\begin{tabular}{|c|c|c|c|}
\hline Subfamília & Tribo & Gênero & $\begin{array}{l}\text { Número de } \\
\text { espécies válidas }\end{array}$ \\
\hline \multirow[t]{5}{*}{ Triatominae } & Alberproseniini & Alberprosenia & $\overline{2}$ \\
\hline & Bolboderini & $\begin{array}{l}\text { Belminus } \\
\text { Bolbodera } \\
\text { Microtriatoma } \\
\text { Parabelminus }\end{array}$ & $\begin{array}{l}8 \\
1 \\
2 \\
2\end{array}$ \\
\hline & Cavernicolini & Cavernicola & 2 \\
\hline & Rhodniini & $\begin{array}{l}\text { Psammolestes } \\
\text { Rhodnius }\end{array}$ & $\begin{array}{r}3 \\
19\end{array}$ \\
\hline & Triatomini & $\begin{array}{l}\text { Dipetalogaster } \\
\text { Eratyrus } \\
\text { Hermanlentia } \\
\text { Linshcosteus } \\
\text { Meccus } \\
\text { Mepraia } \\
\text { Nesotriatoma } \\
\text { Panstrongylus } \\
\text { Paratriatoma } \\
\text { Triatoma }\end{array}$ & $\begin{array}{r}1 \\
2 \\
1 \\
6 \\
6 \\
3 \\
3 \\
14 * \\
1 \\
72 * *\end{array}$ \\
\hline Total & & 18 & 148 \\
\hline
\end{tabular}
* esse gênero possui uma espécie fóssil: P. hispaniolae Ponair Jr., 2013
** esse gênero possui uma espécie fóssil: Triatoma dominicana Ponair
Jr., 2005 hematofagia (Usinger 1944, Lent \& Wygodzinsky 1979, Clayton 1990, Schuh \& Slater 1995, Hypsa et al. 2002, Weirauch, 2008), ainda existem várias dúvidas sobre a origem e evolução dos triatomíneos(Schaefer 1998, 2003, 2005). Schofield (1988) propôs um conceito de origem polifilética dos triatomíneos, ou seja, diferentes ancestrais teriam dado origem aos diferentes grupos de triatomíneos. Segundo esse ponto de vista, a fauna triatomínica Asiática, por exemplo, consistiria de ao menos duas linhagens independentes, derivadas de diferentes ancestrais reduviídeos. A primeira linhagem incluiria algumas espécies de Triatoma, as quais teriam evoluído a partir de um ancestral comum com Triatoma rubrofasciata, uma espécie originária do Novo Mundo e introduzida posteriormente no Velho Mundo através das grandes navegações. A segunda linhagem seria representada pelas espécies do gênero Linshcosteus, uma linhagem supostamente autóctone da Índia. Porém, análises cladísticas moleculares de 57 espécies mostraram que o gênero Linshcosteus e Triatoma rubrofasciata são grupos irmãos (Hypsa et al. 2002), apoiando a hipótese de origem monofilética da subfamília Triatominae. Se ao contrário, a origem for polifilética e, portanto todos os membros da subfamília Triatominae não derivaram de um único ancestral comum, quais seriam as outras subfamílias de Reduviídeos mais proximamente relacionadas aos diversos grupos de triatomíneos? Tentando resolver esse quebra-cabeça evolutivo, diversos cientistas têm usado dados moleculares (sequências de DNA) para fazer inferências sobre o relacionamento filogenético (Garcia \& Powell 1998, Stothard et al. 1998, Lyman et al. 1999, Garcia 1999, Marcilla et al. 2002, Monteiro et al. 2003, Sainz et al. 2004, Paula et al. 2005, 2007 e Weirauch \& Munro, 2009). Embora sejam importantes contribuições e algumas delas sugiram a polifilia ou parafilia de alguns gêneros de Triatominae, a 
maioria dessas publicações está baseada em um número limitado de táxons e, portanto, ainda não podem solucionar as questões da filogenia da subfamília Triatominae como um todo.

Um panorama do estado atual das discussões sobre classificação e evolução dos triatomíneos foi publicado por Schofield \& Galvão (2009). Mais recentemente Patterson \& Gaunt (2010) baseados em análises multi-locus e relógios moleculares voltaram a defender a hipótese de origem monofilética dos triatomíneos. Uma solução definitiva para essa questão deverá ser suportada por análises cladísticas adicionais e mais abrangentes, incluindo também caracteres morfológicos.

\section{Noções de nomenclatura zoológica}

O sistema de nomes aplicados aos táxons animais é chamado de nomenclatura zoológica. Esse sistema é regido pelo Código Internacional de Nomenclatura Zoológica (ICZN, 1999). É composto por uma série de regras e recomendações para compor e utilizar os nomes científicos dos animais. O objetivo do código é que cada táxon tenha um nome estável, único e universal. Existem outros códigos para as áreas de microbiologia e botânica, porém, são independentes uns dos outros.

O código só rege os táxons incluídos nas categorias do grupo família (inclui superfamília, família, subfamília, tribo e qualquer categoria abaixo de superfamília e acima de gênero), do grupo gênero (inclui gênero e subgênero) e do grupo espécie (inclui espécie e subespécie). Os nomes de táxons de outras categorias não estão sujeitos a regras e recomendações e são ignorados pelo Código de Nomenclatura.

Os nomes dos táxons devem ser compostos de palavras que devem ser latinizados. Os nomes das espécies são binominais (p. ex. Triatoma brasiliensis), os das subespécies trinominais (p. ex. Triatoma brasiliensis melanica) e os nomes dos demais táxons uninominais (p. ex. Triatominae). Quando um autor descreve uma nova espécie, se baseia numa amostra de espécimes, que são chamados de tipos. Se a espécie for descrita baseada em um único espécime, este será chamado de holótipo, se o autor descrever um casal de espécimes um será o holótipo (geralmente o macho) e o outro será o alótipo. Se a descrição for baseada numa série maior de espécimes, além do holótipo e do alótipo os demais espécimes serão chamados de parátipos. Caso o autor não designe um holótipo, todos os espécimes estudados serão chamados de síntipos. Os tipos, portanto, tem a função de fixar a aplicação de um nome específico ou subespecífico.

A prioridade sobre um nome, o chamado princípio da prioridade, é uma questão estabelecida pelo Código como tendo início em 1758, ou seja, o ano de divulgação da décima edição do Systema Naturae. Daí em diante, toda a determinação da prioridade na autoria de um nome é feita em função da data de publicação. Este é o princípio mais importante do Código e resolve de maneira simples, problemas nomenclaturais. De dois ou mais sinônimos (dois ou mais nomes para o mesmo táxon) ou homônimos (o mesmo nome aplicado a dois ou mais táxons dentro do mesmo grupo), vale o mais antigo, ou seja, aquele autor que publica um nome pela primeira vez, tem a prioridade de usar esse nome.

Obviamente, há diversas outras questões nomenclaturais que são detalhadamente explicitadas pelo código, portanto, o texto de estudo de nomenclatura deve ser o próprio Código, preferencialmente em sua última edição (ICZN, 1999). 


\section{Sistemática tradicional x Sistemática filogenética}

A sistemática é o campo da biologia que busca ordenar a biodiversidade e, para isso, utiliza métodos de classificação. É, portanto, a base para estudos nos demais campos da biologia. $\mathrm{Na}$ classificação tradicional proposta por Carolus Linnaeus (1707-1778), o agrupamento entre os organismos está baseado apenas no grau de similaridade entre eles. Nesse sistema de classificação as características fenotípicas são utilizadas comparativamente para separar ou agrupar os organismos.

A publicação da revolucionária teoria da evolução de Charles Darwin (1809-1882), mostrou que todos os organismos vivos na Terra são o resultado da evolução e estão relacionados entre si. O problema é que as espécies mais semelhantes morfologicamente não são necessariamente as mais aparentadas entre si. Uma classificação pode ser considerada natural, se define grupos cujo parentesco entre seus membros seja maior do que entre os membros deste e de outros grupos.

A filogenia é o estudo das relações de parentesco entre os organismos e dos caminhos trilhados pela evolução, o cladismo foi o método desenvolvido pelo entomólogo alemão Willi Hennig (19131976) que promoveu uma grande revolução na taxonomia do século 20 , pois possibilitou a identificação de caracteres primitivos e derivados indispensáveis para a construção das árvores que mostram uma relação evolutiva. Hennig defendia que todos os táxons propostos devem ser monofiléticos, ou seja, formados hipoteticamente por todos os descendentes de um ancestral comum exclusivo. A representação gráfica desse tipo de relacionamento é chamada cladograma (Figura 3.6). Essa proposta vem sendo assimilada ao longo dos últimos anos, mas as categorias criadas por Linnaeus, sem nenhuma implicação evolutiva, continuam sendo usadas. A figura 3.7 mostra um hipotético encontro entre o criador do primeiro sistema consistente de classificação (Linnaeus), o idealizador da sistemática filogenética (Hennig) e o criador da teoria da evolução. Nesse "encontro" Darwin sorri da situação criada pela sua teoria, que foi reforçada pelo revolucionário método criado por Hennig. Linnaeus estaria assustado com a possibilidade de substituição do seu sistema de classificação por outro, baseado no método criado por Hennig (para mais

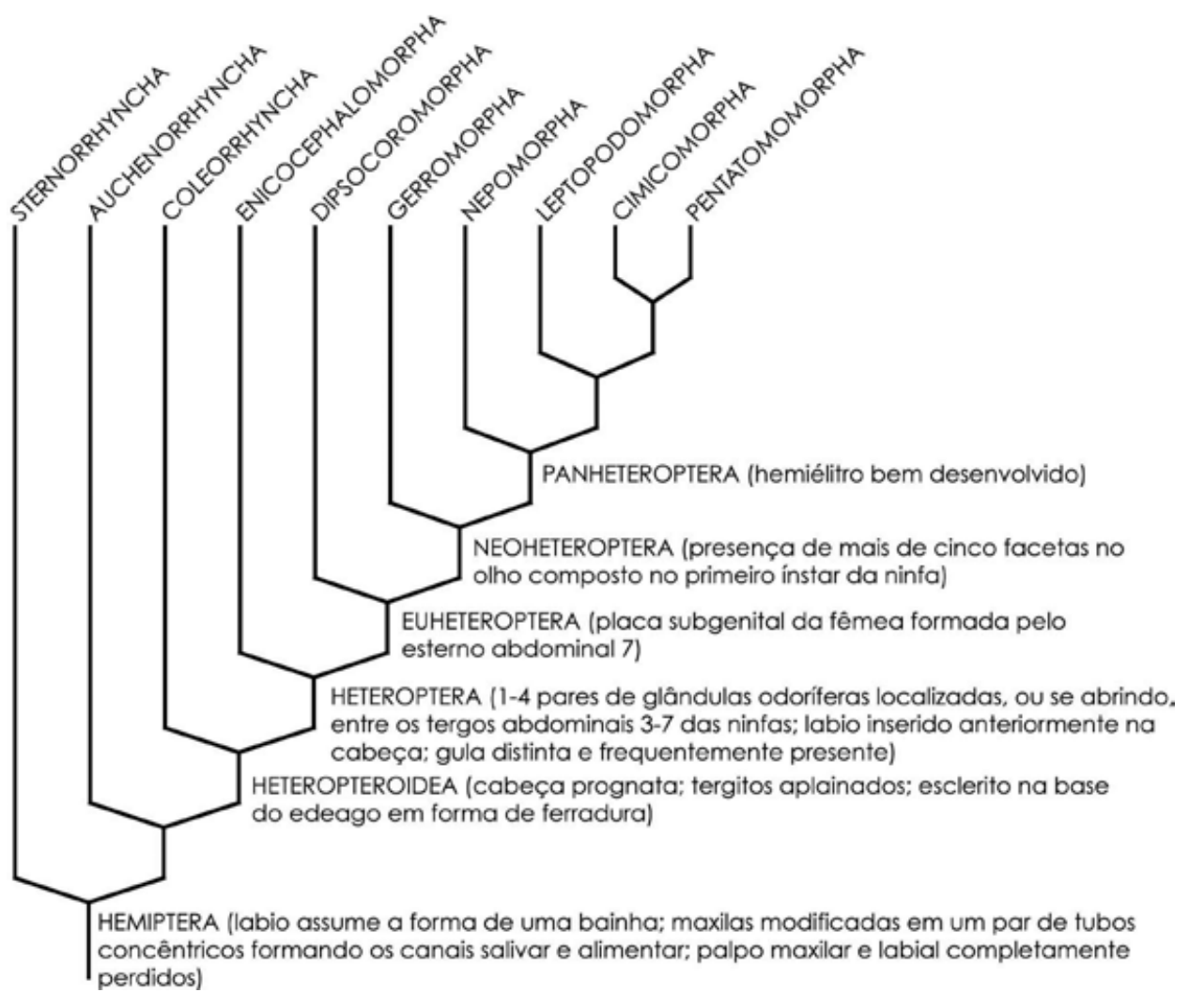

Figura 3.6: Exemplo de cladograma, uma representação gráfica do relacionamento de um grupo de táxons incluindo seu(s) ancestral(is) comum(uns). Cladograma redesenhado de Cassis \& Schuh (2009), representando um esquema de relacionamento filogenético para a ordem Hemiptera. 
detalhes sobre a teoria evolucionista de Darwin e a sistemática filogenética de Hennig veja capítulo 13).

É importante ressaltar que as análises cladísticas necessitam sempre de uma hipótese a priori de monofiletismo a ser testada para um determinado grupo e quem fornece essa informação é geralmente a taxonomia tradicional. Outro aspecto interessante da taxonomia tradicional é seu caráter utilitarista, o que torna seus resultados mais facilmente compreensíveis para um público não acadêmico.
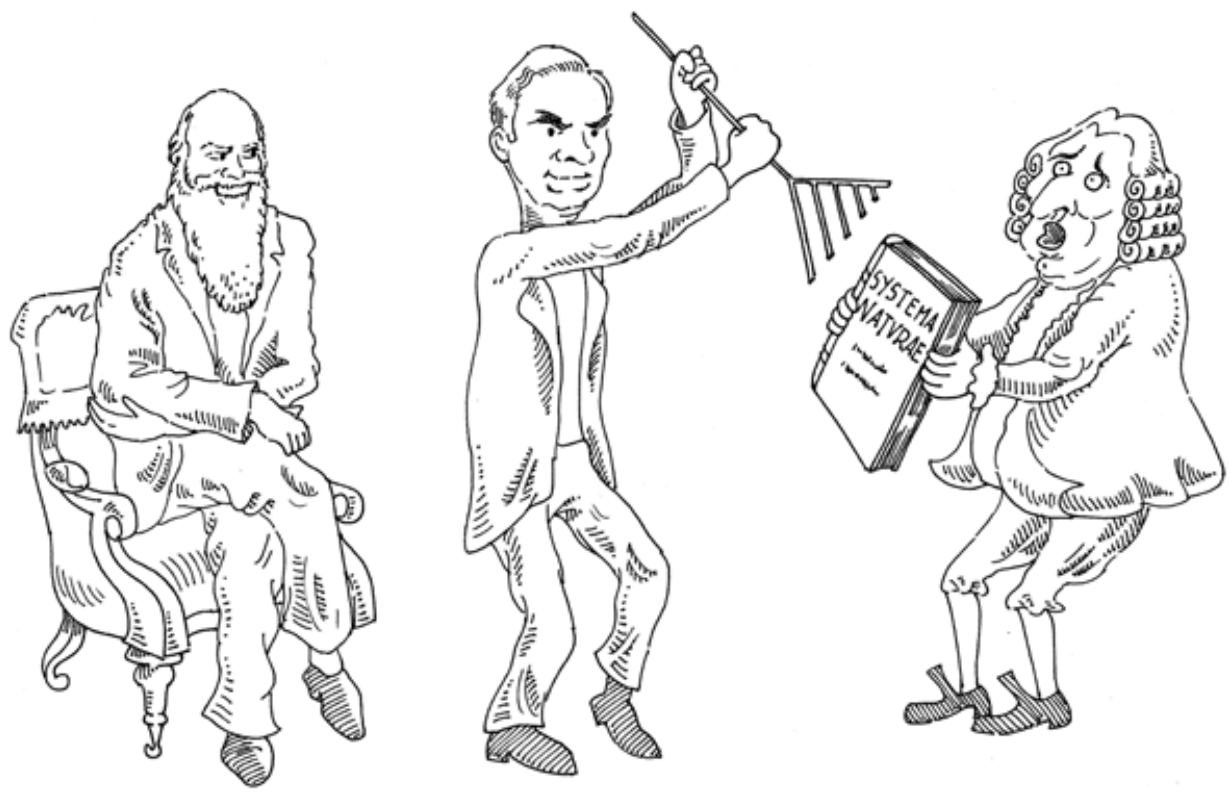

Figura 3.7: Charge retratando um hipotético encontro entre três das mais importantes personalidades da história da biologia: C. Darwin, W. Hennig e C. Linnaeus. 